\title{
Experimental determination of the heat transfer coefficient during evaporation and boiling of thin liquid film
}

\author{
Anastasia Islamova ${ }^{1, *}$ \\ ${ }^{1}$ National Research Tomsk Polytechnic University, 634050 Tomsk, Russia
}

\begin{abstract}
Thin films evaporation of distilled water, ethanol and HFE-7100 liquid was experimentally studied. The dependences of heat transfer coefficients in time were determined. It has been established that with a decrease in the layer thickness of distilled water and ethanol, the heat transfer coefficient increases. For the HFE liquid, the nature of the change is different: as the time increases, the heat transfer coefficient decreases.
\end{abstract}

\section{Introduction}

At present, development of industries (metallurgy, microelectronics, etc.) is proceeding along the path of increasing the energy saturation of equipment [1-3]. One particular problem of technique is the creation of systems for thermal operating conditions of the equipment $[4,5]$. To solve this, it is necessary to create energy efficient systems based on phase transitions [68]. Thin films of liquids are used in industrial technologies, for example, for cooling locally heated surfaces $[9,10]$.

The heat transfer coefficient determines the intensity of heat transfer and characterized the liquid-vapor or liquid-air interface. The layer thickness is one of the significant factors affecting the heat transfer coefficient under evaporation conditions of a thin liquid film on the heat exchange surface.

The objective of the present work was to determine experimentally the change of the heat transfer coefficient in time when thin engineering fluids evaporate.

\section{Methods and materials}

The research was conducted on the experimental setup simulating the conditions of boiling and evaporation of liquid thin layers [11]. The principle of its operation and the procedure for carrying out the experiments are given in [12].

In the experiments, we used a stainless steel substrate with a diameter of $50 \mathrm{~mm}$ and a thickness of $2 \mathrm{~mm}$. Distilled water, ethanol and methoxy-nonafluorobutane (HFE-7100) were used as the test liquids. The material was chosen due to wide usage in heat exchangers, significant differences in thermal properties (the effect of properties on the characteristics of

\footnotetext{
Corresponding author: agi2@tpu.ru
} 
heat transfer). The initial thickness of the layer for ethanol was $1 \mathrm{~mm}$, distilled water and liquid HFE-7100 was $1.5 \mathrm{~mm}$, which corresponds to liquid volumes of $2 \mathrm{ml}$ for ethanol and $3 \mathrm{ml}$ for distilled water and HFE-7100 liquid. The choice of layer thickness was due to the ratio of adhesion forces to internal cohesion, which prevented a uniform spreading of the layer over the substrate surface. It is revealed that the stainless steel substrate used in the experiment investigation was not wetted by distilled water (contact angle more than $\left.90^{\circ}\right)$.

The heat flux from the surface of heat exchange to the layer was determined from the temperature gradient in two different sections along the height of the plate:

$$
Q=\lambda \frac{\pi d^{2}}{4 l} \cdot \Delta T
$$

where $\lambda$ is the thermal conductivity of the copper plate, $\mathrm{W} /(\mathrm{m} \cdot \mathrm{K}) ; l$ is thickness of copper plate $(10 \mathrm{~mm}), \mathrm{m} ; d$ is plate diameter $(50 \mathrm{~mm}), \mathrm{m} ; \Delta T$ is the temperature gradient between the upper and lower sections of the plate, $\mathrm{K}$. The temperature of the plate section is determined as the average value of the thermocouple readings located in one cross section in height.

When analyzing data, it was assumed that the curvature of the interface with a change in layer height occurs only in a very narrow region at the edge of the layer.

The density of the heat flux was determined by the formula:

$$
q=\frac{Q}{S}, \frac{\mathrm{W}}{\mathrm{m}^{2}}
$$

where $S$ is the heat exchange surface area, $\mathrm{m}^{2}$.

The heat transfer coefficient was calculated by the formula:

$$
\alpha=\frac{q}{T_{S}-T_{W}},
$$

where $q$ is heat flux density, $\mathrm{W} / \mathrm{m}^{2} ; T_{S}$ is vapor temperature above the surface of the liquid, ${ }^{\circ} \mathrm{C} ; T_{W}$ is the temperature of the substrate was assumed to be equal to the temperature of the upper surface of the metal plate in the center, ${ }^{\circ} \mathrm{C}$.

\section{Results and discussion}

The dependences of heat transfer coefficient on time for ethanol, distilled water and HFE7100 liquid are presented in Figures 1-3. 


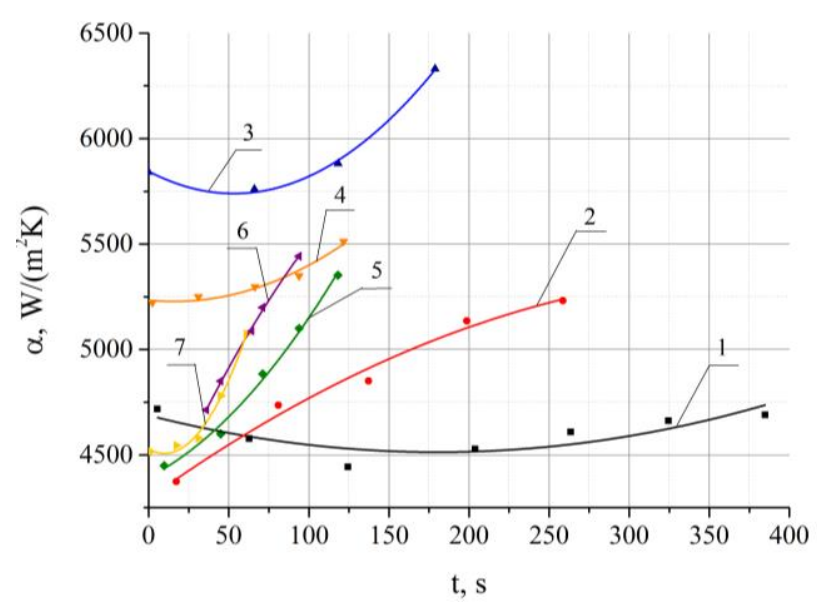

Fig. 1. Dependences of ethanol heat transfer coefficient on the time at the substrate temperature: $1-65{ }^{\circ} \mathrm{C}, 2-70{ }^{\circ} \mathrm{C}, 3-75^{\circ} \mathrm{C}, 4-80{ }^{\circ} \mathrm{C}, 5-85^{\circ} \mathrm{C}, 6-90^{\circ} \mathrm{C}, 7-95^{\circ} \mathrm{C}$.

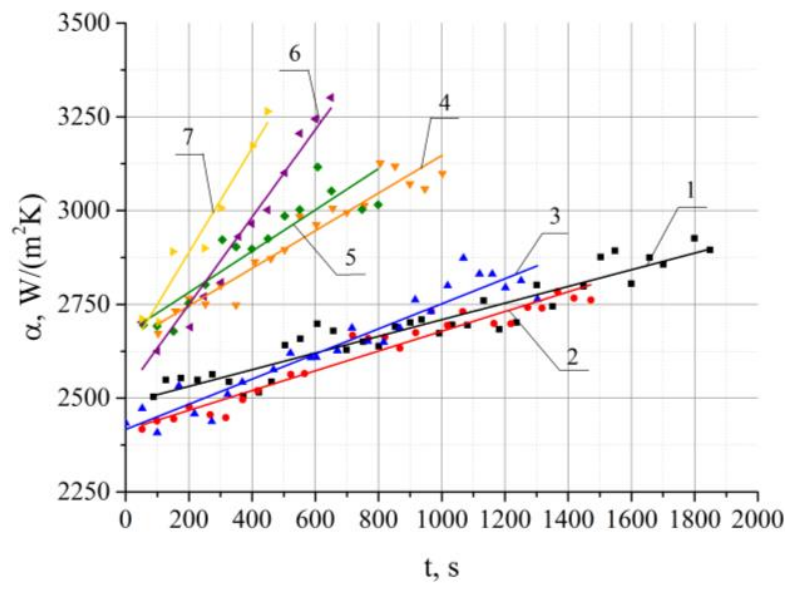

Fig. 2. Dependences of distilled water heat transfer coefficient on the time at the substrate temperature: $1-70{ }^{\circ} \mathrm{C}, 2-75^{\circ} \mathrm{C}, 3-80^{\circ} \mathrm{C}, 4-85^{\circ} \mathrm{C}, 5-90{ }^{\circ} \mathrm{C}, 6-95^{\circ} \mathrm{C}, 7-100{ }^{\circ} \mathrm{C}$.

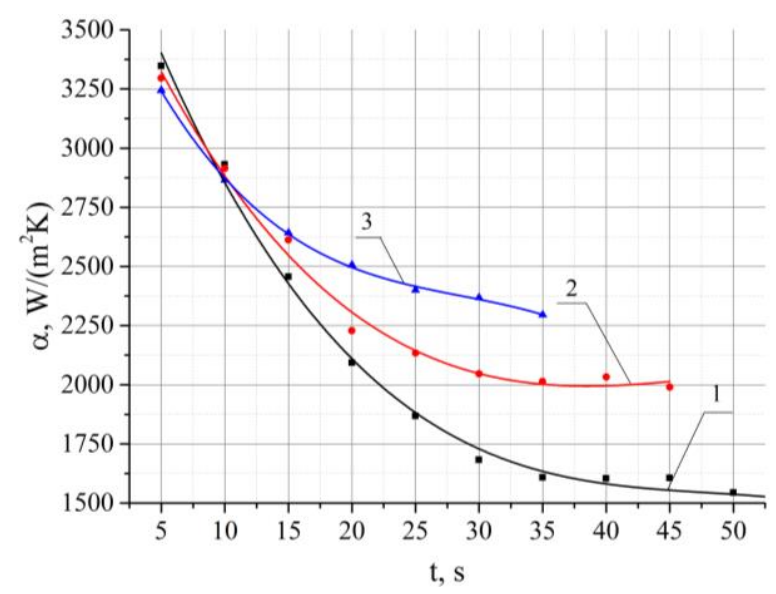

Fig. 3. Dependences of HFE-7100 heat transfer coefficient on the time at the substrate temperature: $1-55^{\circ} \mathrm{C}, 2-60{ }^{\circ} \mathrm{C}, 3-65^{\circ} \mathrm{C}$. 
According to the analysis of dependences (Fig. 1-3) allows us to conclude that with a decrease in the thickness of the liquid layer, the heat transfer coefficient increases for ethanol and distilled water. The rate of change in the heat transfer coefficient is shown in Fig. 4.

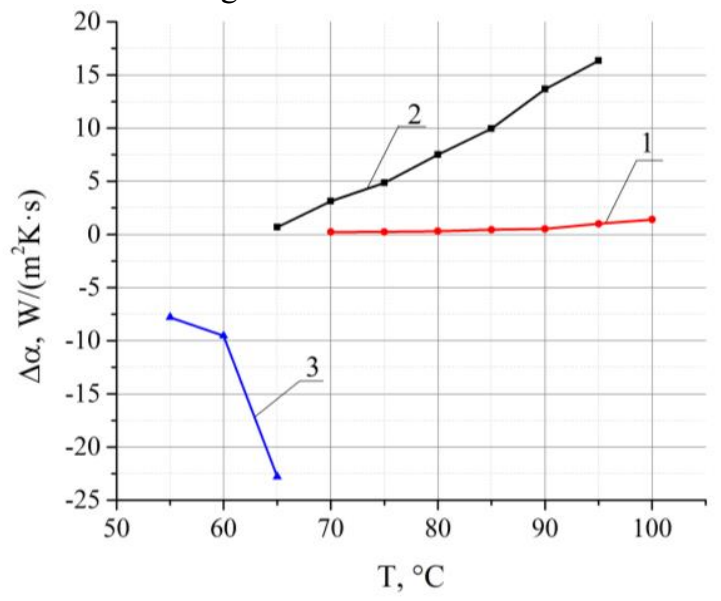

Fig. 4. The rate of change in the heat transfer coefficient from the substrate temperature. Liquids: 1 - distilled water, 2 - ethanol, 3 - HFE 7100.

As seen in Fig. 4, the heat transfer coefficient for ethanol and distilled water increases with increasing temperature. What is more, for ethanol this change is more significant (up to $15 \mathrm{~W} /\left(\mathrm{m}^{2} \mathrm{Ks}\right)$.

For ethanol, the heat transfer coefficient varies from 4500 to $6250 \mathrm{~W} /\left(\mathrm{m}^{2 \circ} \mathrm{C}\right)$, and at $65{ }^{\circ} \mathrm{C}$ it practically does not change during the experiment. At temperatures from 70 to $95{ }^{\circ} \mathrm{C}$ with an increase in the time, the coefficient increases by $250-1000 \mathrm{~W} /\left(\mathrm{m}^{2 \circ} \mathrm{C}\right)$ as a function of temperature. The latter is explained by the fact that temperatures over $78^{\circ} \mathrm{C}$ are greater than the boiling point. When underheated to boiling $\left(10-15^{\circ} \mathrm{C}\right)$, the heat transfer coefficient varies insignificantly compared with evaporation at boiling point and overheating. With a decrease in underheating to the boiling point, a significant increase in the heat transfer coefficient occurred. At temperature of $75^{\circ} \mathrm{C}$ (close to the boiling point), the heat transfer coefficient is the maximum $5750-6250 \mathrm{~W} /\left(\mathrm{m}^{2 \circ} \mathrm{C}\right)($ Fig. 1). At temperatures above the boiling point, the coefficient decreases, and with a superheat of $10-20{ }^{\circ} \mathrm{C}$, the nature of the latter's change is the same.

Three regions of the change in the heat transfer coefficient for distilled water could be distinguished (Fig. 2): at low temperatures for distilled water $\left(70-80^{\circ} \mathrm{C}\right)$ is the first region of underheating (in 500 seconds the heat transfer coefficient changes by $100 \mathrm{~W} /\left(\mathrm{m}^{2 \circ} \mathrm{C}\right)$ ); at temperatures $85,90{ }^{\circ} \mathrm{C}$ - the second region of underheating, at the same time the coefficient changes by $200 \mathrm{~W} /\left(\mathrm{m}^{2 \circ} \mathrm{C}\right)$; and at $95,100{ }^{\circ} \mathrm{C}$ is the third region of underheating, the coefficient changes by $500-600 \mathrm{~W} /\left(\mathrm{m}^{2 \circ} \mathrm{C}\right)$. At boiling (temperature $100{ }^{\circ} \mathrm{C}$ ) the heat exchange processes took place most intensively; therefore the change in the heat transfer coefficient is maximal.

For the liquid HFE, the nature of the change is different: with increasing time, the coefficient decreases by $1000-1750 \mathrm{~W} /\left(\mathrm{m}^{2 \circ} \mathrm{C}\right)$. The latter is due to the rapidity of the evaporation process, the large molecular mass of the liquid HFE and properties specificity of the refrigerant. In 30-35 seconds, a quasi-stationary regime occurs, the heat transfer coefficient varies insignificantly, as can be seen from Fig. 3. 


\section{Conclusion}

Experimental studies on the thin layers evaporation of ethanol, distilled water, HFE-7100, have been carried out. The changes in the heat transfer coefficient over time were determined. It has been established that with decrease in the thickness of the liquid layer, the heat transfer coefficient increases for ethanol (from 4500 to $6250 \mathrm{~W} /\left(\mathrm{m}^{2 \circ} \mathrm{C}\right)$ ) and distilled water (from 2400 to $\left.3400 \mathrm{~W} /\left(\mathrm{m}^{2 \circ} \mathrm{C}\right)\right)$. For the HFE liquid, the nature of the change is different. As the time increases, the heat transfer coefficient decreases by $1000-1750 \mathrm{~W} /\left(\mathrm{m}^{2 \circ} \mathrm{C}\right)$.

The reported study was supported by RFBR, research project No. 18-38-00315 mol_a.

\section{References}

1. D. O. Glushkov, G. V. Kuznetsov, P. A. Strizhak, Combust. Explos. Shock Waves, 50, 670 (2014), DOI: 10.1134/S0010508214060082

2. D. V. Feoktistov, E. A. Vympin, A. E. Nurpeiis, MATEC Web Conf. 72, 01081 (2016), DOI: $10.1051 /$ matecconf $/ 20167201081$

3. A. A. Sivkov, A. Pak, I. Shanenkov, Y. Kolganova, I. Prosvirin, Adv. Mat. Res. 880, 36 (2014), DOI:10.4028/www.scientific.net/AMR.880.36

4. E. G. Orlova, D. V. Feoktistov, G. V. Kuznetsov, K. O. Ponomarev, European J. Mech. - B/Fluids, 68, 118 (2018), DOI: 10.1016/j.euromechflu.2017.12.002

5. I. N. Madyshev, O. S. Dmitrieva, A. V. Dmitriev, A. N. Nikolaev, CAPE, 52, 299 (2016), DOI 10.1007/s10556-016-0189-2

6. G. V. Kuznetsov, D. V. Feoktistov, E. G. Orlova, S. Y. Misyura, V. S. Morozov, A. G. Islamova, Int. J. Heat Mass Transfer, 68, 118 (2018), DOI: 10.1016/j.euromechflu.2017.12.002

7. V. E. Nakoryakov, S. Y. Misyura, J. Eng Thermophys. 25, 24 (2016), DOI: 10.1134/S1810232816010033

8. S. Y. Misyura, Sci. Rep. 6, 30324 (2016), DOI: 10.1038/srep30324

9. K. Ponomarev, E. Orlova, D. Feoktistov, EPJ Web Conf. 110, 01060 (2015), DOI: 10.1051/epjconf/201611001060

10. D. V. Zaitsev, M. L. Aviles, H. Auracher, O. A. Kabov, Microgravity Sci. Technol. 19, 71 (2007), DOI: 10.1007/BF02915756

11. D. Feoktistov, S. Misyura, A. Islamova, K. Batishcheva, V. Velicanov, EPJ Web Conf. 159, 0011 (2017), DOI: 10.1051/epjconf/201715900011

12. V. D. Velicanov, E. G. Orlova, A. S. Saigash, O. S. Korneva, MATEC Web Conf. 72, 01028 (2016), DOI: 10.1051/matecconf/2016720102 